\title{
Foucault escritor: 0 arquivista e o eu-enunciado na arqueologia
}

\author{
Foucault writer: the archivist and the I-enunciated in archeology \\ Carla Luzia Carneiro BORGES \\ Universidade Estadual de Feira de Santana (UEFS) \\ Renailda Ferreira CAZUMBÁ \\ Universidade Estadual de Feira de Santana (UEFS)
}

https://orcid.org/0000-0002-3396-1962

\begin{abstract}
RESUMO: Em “A Arqueologia do saber", Michel Foucault (2004) destaca, ao se definir como escritor e arquivista, o sujeito como um ser das dispersões e contradições, entre saber e poder, confrontos e medos, interdições e resistências, determinações e acontecimentos. Colocando em questão a própria razão de por que escrever aquele livro, o Foucault insurgente, faz aparecer um eu-enunciado e arquivista. Analisamos este processo de subjetivação de Foucault, seu movimento em espiral, no interior de sua obra, destacando os enunciados que acusam o acontecimento da escritura foucaultiana. Este artigo visa dar mais visibilidade a este sujeito que enuncia a si, a fim de explicar e desenvolver um método de trabalho (o arqueológico), no qual o autor se confronta com elementos de um dispositivo que produz linhas de força. Essas linhas enfocam seu projeto de empreender o quadro teórico-metodológico da produção do saber.
\end{abstract}

PALAVRAS-CHAVE: Foucault; subjetivação; Eu-enunciado; arquivo; Arqueologia.

ABSTRACT: In The Archeology of Knowledge, Michel Foucault (2004) highlights, by defining himself as a writer and an archivist, the subject as a being of dispersions and contradictions, between knowledge and power, confrontations and fears, interdictions and resistance, determinations and events. Questioning the reason itself on why writing that book, the insurgent Foucault as an I-statement and archivist. We analyze Focault's process of subjectivation, his spiral movement, within his work, emphasizing the statements which accuse the event on the foucauldian writing. This article aims to improve visibility concerning the enunciative subject, in order to explain and develop a working method (the archeological one) in which the author confront himself with elements of a device that produces lines of force. These lines focus on his project to undertake the theoretical and methodological framework of knowledge production.

KEYWORDS: Foucault; subjectivation; I-statement; archive; Archeology.

\section{Introdução}

Na escrita, não se trata da manifestação ou da exaltação do gesto de escrever; não se trata da amarração de um sujeito em uma linguagem; trata-se da abertura de um espaço onde o sujeito que escreve não para de desaparecer (FOUCAULT, 2015, p. 272). 
Pesquisadores de diversas áreas celebraram com entusiasmo, em 2019, o cinquentenário de "A Arqueologia do saber" (2004) e ressaltaram a importância desta obra para a compreensão do pensamento de Michel Foucault de maneira tal que a análise arqueológica demarca uma das facetas da teoria do pensador francês. Neste livro publicado originalmente com o título "L'archéologie du Savoir" (Paris Gallimard, 1969), Foucault evidencia os caminhos, conceitos e métodos de análise que batizou de "arqueologia". Ao delinear a utilidade dessa nova analítica do discurso, vemos o sujeito-escritor que se examina no ato da escritura e se interroga sobre o funcionamento da descrição arqueológica, hesita diante da proposição de conceitos e expõe questionamentos dirigidos à própria análise que propõe e, sobretudo, duvida se as análises que empreende seriam distintas de outras que já descreveram e analisaram a linguagem: o "que outras descrições não seriam capazes de dar? Qual é a recompensa de tão árdua empresa?" (FOUCAULT, 2004, p. 154). Neste caso, o eu sujeitoarquivista também se enuncia, dando a ver que existe um já-dito sobre o discurso no trajeto dos estudos da linguagem e da filosofia.

"A Arqueologia do Saber" é um livro primordial para a compreensão do pensamento de Michel Foucault e não representa uma leitura acessível, na medida em que a forma de construção textual obedece à descontinuidade e à não-linearidade que caracterizam o pensamento e a escrita do autor. Ao escrever, Foucault deixa evidente este movimento singular que nomeia de descrição arqueológica. Noções como as de discurso vêm acompanhadas de outras noções como as de "formações discursivas", "enunciados", "positividade", "arquivo". Foucault ainda mobiliza domínios conceituais que estão nas bases de seu trabalho arqueológico como "campo enunciativo" e "práticas discursivas", os quais o autor afirma ser na verdade um "estranho arsenal", uma "bizarra maquinaria", com a qual vem trabalhando para compor a especificidade da análise arqueológica (FOUCAULT, 2004, p. 153- 154).

Dessa forma, conceitos como os de descontinuidade, dispersão, positividade, $a$ priori histórico compõem a singularidade do método ao qual Foucault acrescenta outros componentes investigativos para o estudo da linguagem e são delineados no decorrer do texto na forma de questionamentos constantes, hesitações, retornos e suposições que marcam o modo como Foucault constrói sua escritura quase de forma narrativa.

O desafio de ler "A Arqueologia do Saber" reside em entrar o leitor em contato com a perspectiva nova de tratar os fatos da linguagem da qual Foucault se encarrega, mas, sobretudo, com o desafio do sujeito-escritor e do arquivista que emerge no trajeto 
da escrita, enquanto elabora a análise discursiva que não trata apenas dos fatos da linguagem, mas de objetos como o livro e a obra, das disciplinas como a medicina, a literatura e a história; da definição "não os pensamentos, as representações, as imagens, os temas, as obsessões que se ocultam ou se manifestam nos discursos", mas tratar dos "próprios discursos enquanto práticas que obedecem a regras" (FOUCAULT, 2004, p. 157). Reitera em outro texto: “[...] meu objeto não é a linguagem, mas arquivo, ou seja, a existência acumulada dos discursos" (p. 74).

Desta forma, quando pensamos hoje as discursividades que envolvem as práticas de leitura e escrita literárias, consideramos a rede de posições e relações de saber/poder que envolvem os sujeitos e sujeitas que leem e escrevem, as instituições como as escolas e as editoras e, especialmente, os enunciados efetivamente pronunciados sobre a leitura e literatura que formaram arquivos e balizam a nossa visão do que é /como e quem lê e escreve literatura hoje. Por isso, amparamo-nos em Foucault quando este ressalta que a arqueologia é análise do discurso em sua modalidade de arquivo, ou seja, o conjunto dos discursos que foram efetivamente produzidos e que são retomados, ampliados, esquecidos e lembrados na sociedade a partir de uma lei de descontinuidade. O interesse é saber como os discursos têm se manifestado em enunciados, mantidos e transformados nos diferentes domínios do saber.

A noção foucaultiana de arquivo funciona como um conceito operacional, a partir do qual o autor estabelece as descontinuidades das unidades discursivas presentes no campo das ciências humanas, sobretudo para refletir sobre a positividade do discurso das ciências. Com base na noção de arquivo, os enunciados abordados são aqueles efetivamente pronunciados com base nas regras de seu surgimento na sociedade. Na lei do arquivo, os enunciados são descritos segundas as leis de surgimento, de existência e de funcionamento coerentes com as leis de atualização e transformação históricas. No arquivo, os enunciados não teriam existência apenas enquanto o acúmulo de fatos que falariam por si e teriam funcionamento no passado.

O autor propõe que a descrição dos discursos tenha o poder de analisar o que realmente foi dito e que foi inscrito na trama singular da história a partir de um funcionamento do que é dito como textos preservados num espaço físico tampouco em forma de sequências linguísticas, proposições ou frases. Com base no arquivo, Foucault institui que a análise discursiva trata o que é dito como eventos originais que se instituem na rede de eventos discursivos e não-discursivos. Por este caminho, o que 
importa na análise dos discursos é a singularidade do que é dito, pois os enunciados não representam elementos residuais da linguagem. A descrição dos enunciados pressupõe observar nas práticas discursivas os "sistemas que instauram os enunciados como acontecimentos" (FOUCAULT, 2004, p. 146) e que possibilita ao analista do discurso a reflexão sobre o que somos no momento presente. O arquivo são, segundo Foucault, "sistemas de enunciados", configuram-se como "acontecimentos (tendo suas condições e seu domínio de aparecimento) e coisas (compreendendo sua possibilidade e seu campo de utilização)" (p. 146).

$\mathrm{Na}$ rede discursiva da análise enunciativa, o dito é tratado na perspectiva de monumentos, de acontecimentos únicos, irrepetíveis, isto é, singulares como enunciados: "chamarei de arquivo não a totalidade de textos que foram conservados por uma civilização [...] mas o jogo de regras que, em uma cultura, determinam o aparecimento e o desaparecimento de enunciados, sua permanência e seu apagamento sua existência paradoxal de acontecimentos e coisas" (FOUCAULT, 2013, p 98-99). Com base na noção de arquivo, o filósofo delibera sobre o funcionamento dos discursos na sociedade para que se perceba que o que é dito está sujeito a atualizações e a retomadas no curso dos acontecimentos discursivos. O arquivo, para Foucault, não possui uma existência física, material e não pode ser encontrado na totalidade dos textos que foram preservados por uma civilização, nem no conjunto das marcas que se puderam salvar de suas ruínas. $O$ arquivo na perspectiva da análise foucaultiana, subsiste no jogo e no conjunto de regras que determinam, em uma cultura, o surgimento e o desaparecimento de enunciados, sua remanescência e eliminação, sua existência paradoxal de acontecimentos e de coisas.

$\mathrm{O}$ arquivo constitui uma forma de memória, mas uma memória constituída como monumento, reelaborada no presente, sincrônica porque pressupõe o embate de vozes dissidentes à memória oficial, construída por processos de atualização e dinamismo, cortes e fissuras às narrativas eleitas pelos discursos institucionais, ligada à reflexão das transformações do tempo presente, mas que, acima de tudo, implica relações de saber/poder que instituem o que será lembrado e esquecido.

Perguntamo-nos, então, inicialmente, como se constitui este arqueólogoarquivista na escrita de "A Arqueologia do Saber"? Seguimos o percurso da leitura sobre o enunciado na descrição arqueológica de Foucault-arquivista, entretanto, mediada também pelo olhar lançado por Gilles Deleuze sobre a arqueologia no ensaio "Foucault", publicado em 1986. Depois, apresentaremos algumas pistas para se pensar 
a noção de eu-enunciado, concebida a partir do movimento feito por Foucault, enquanto escritor de "A Arqueologia do Saber".

\section{O arquivista e o Enunciado n' A arqueologia}

De início, comparemos a escrita de Foucault sobre o enunciado em "A Arqueologia do Saber" ao movimento de uma serpente ao deslizar pelo caminho traçando uma linha sinuosa numa estrada, numa areia fina que é riscada e cortada pela marca efêmera do corpo do animal na procura, caça ou captura de uma presa. Esta é a sensação que temos ao lermos o capítulo "O enunciado e o arquivo". Observamos o escritor e o filósofo que caminham como a serpente deixando o rastro de curvas, descontinuidades, retornos ao começo, hesitações e cortes que insinuam seu percurso textual e teórico desconcertante. Olhemos para ambos: o filósofo e o escritor interrogam o próprio caminho que traçaram do início para abordar o discurso da forma como têm pensado, quando aceitam o "risco" de "articular a grande superfície os discursos" e as figuras um tanto "pouco estranhas das formações discursivas". Foucault, filósofo e escritor, assume a medida de precaução do seu texto que denuncia a posição singular do seu discurso, enunciado no "espaço branco de onde falo" e ainda “incerto e tão precário", conforme alega na "Introdução". Este "espaço branco" que Foucault assume se inscreve no embate discursivo e do saber, do qual ele falava ainda com precaução, porque antevia os perigos e limites de mover-se na ordem instituída dos métodos e conceitos das ciências e das disciplinas: "Daí, a maneira precavida, claudicante deste texto: a cada instante, ele se distancia, estabelece medidas de um lado e de outro, tateia em direção a seus limites, se choca com o que não quer dizer, cava fosso para definir seu próprio caminho" (FOUCAULT, 2004, p. 19). Foucault admite que abriu mão, por um tempo, por questão de "método" das medidas e caminhos convencionais de abordar a linguagem: "as unidades tradicionais do livro e da obra"; "a unidade de leis de construção do discurso" [...] e a organização formal que disso resulta; "a situação do sujeito falante" e "o a priori de um conhecimento" (FOUCAULT, 2004, p. 89) que são relacionados às definições de discurso marcando o sujeito e o lugar das experiências, ao mesmo tempo em que marca o seu lugar deste eusujeito que escreve.

Mediante uma construção perigosa do período e texto, pois refuta conceitos e orientações teóricas antes de apresentar os princípios que condizem com a arqueologia, o escritor e filósofo, também arquivista vai revisitando temas pertinentes à ciência da 
linguagem que se propôs a contrapor e vai retomando as proposições que trouxe desde o início do livro como o limiar de sua forma de ir pensando, sobre por qual obra "A Arqueologia do Saber" será conhecida definitivamente na trajetória do pensamento de Foucault: esteira e lastro dos conceitos foucaultianos. O escritor-filósofo-arquivista não se apieda do leitor e apenas levanta suspeita, apenas insinua o caminho que pretende realmente traçar para a abordagem discursiva: "as regras de formação" do discurso; "o sistema de emergência dos objetos" e de "aparecimento e de distribuição dos modos enunciativos". (FOUCAULT, 2004, p. 89). Depois de escorregar pela escrita sinuosa de retomada de conceitos e refutação de proposições, Foucault anuncia o propósito que vinha perseguindo até este ponto da obra: descrever os "enunciados". Buscando conduzir à noção de enunciado, mas sem dar essa pista ao leitor, o arquivista pergunta: "se o enunciado é a unidade elementar do discurso, em que consiste?" Quais sãos os seus traços distintivos? Cauteloso se mostra e nos informa que foi construindo o conceito, à medida que ia avançando no texto para evitar uma ingenuidade do seu ponto de partida. E nos damos conta de que no decorrer do livro, enquanto definia o discurso, abordava o conceito de "formação". Foucault explica que o enunciado é uma formação que se liga a uma série de enunciados que o precedem e aos quais se refere, atualizando-os. O campo associado, ou domínio de memória, segundo o autor, é condição para a existência e para a atualização de um enunciado.

A abordagem discursiva desenvolvida por pelo filósofo, a partir de conceitos como o de enunciado e de arquivo, provocaram reações adversas na filosofia. Sem nomear de forma direta "as pessoas rancorosas" que o comparam a um novo representante do estruturalista, no ensaio "Foucault", Gilles Deleuze (2005) discorre sobre as reações surgidas quando da irrupção das ideias e dos métodos da arqueologia, reações que o nomearam de "novo arquivista". A leitura de Deleuze (2005, p.13) incide sobre a noção de enunciado e enfatiza o quanto este conceito é caro na trajetória do autor: “[...] dizem que é um epígino de Hitler". Deleuze fala do desconforto que a teoria foucaultiana causou em diferentes campos do conhecimento, a ponto de o autor ser comparado a um opositor dos direitos do homem e um "farsante" que se apoia nos textos sagrados e nem cita os grandes filósofos. Outros, para Deleuze, por outro lado, celebram algo novo na filosofia.

Deleuze faz uma avaliação positiva sobre o método que Foucault desenvolve na prática arqueológica, particularmente no que se refere à abordagem foucaultiana do enunciado neste livro interessado na positividade do saber. Mostra-se irônico como se 
risse da forma como Foucault constrói a sua arqueologia sem dar pistas ao leitor que, entretanto, intuirá e fará leituras possíveis para a obra do autor. Deleuze conforta o leitor: "É normal que sintamos certa inquietude. Pois o arquivista, de propósito, não dá exemplos" (DELEUZE, 2005, p.14). É, entretanto, incisivo na defesa de Foucault por descartar as frases e as proposições e se ocupar exclusivamente do enunciado: "O novo arquivista anuncia que só vai se ocupar dos enunciados”. (IDEM, p. 13). Para Deleuze, a arqueologia funciona como base para a compreensão da linguagem, porém em um nível diferenciado dos aspectos formais e internos da língua. Em vista da abordagem discursiva com base na descrição do enunciado, Deleuze descreve Foucault como o novo arquivista.

Deleuze elucida como Foucault adota a descrição do enunciado como caminho principal para a configuração do método arqueológico. De tal modo, Deleuze revisita uma passagem do texto na qual Foucault demonstra que uma sequência de elementos linguísticos apenas constitui-se em um enunciado se estiver imersa em um campo enunciativo, em que essa mesma sequência apareça como elemento singular. Deleuze concentra-se na definição do enunciado delineada na arqueologia foucaultiana e comenta o fato de que o enunciado é singular, mas que repetição é uma caraterística que distingue melhor o enunciado de outras formações do discurso. Tal repetição do enunciado se constitui "de forma estrita" e não é "em virtude das" condições externas que possam afetá-lo, mas em razão da "própria materialidade interna que faz da repetição a força característica do enunciado" (DELEUZE, 2005, p. 23). Esclarece-nos que "o enunciado se define sempre através de uma relação específica como uma outra coisa de mesmo nível que ele, isto é, uma outra coisa que concerne a ele próprio" (p. 23; grifos do autor). A leitura de Deleuze não nos esclarece muito até este ponto do texto. Mas seguimos persistentes.

Desta forma, no parágrafo seguinte, Deleuze ajuda-nos a compreender que existe uma condição de "identidade" e de "diferença" que constitui o enunciado: "O enunciado é em si mesmo repetição, embora o que ele repete seja 'outra coisa' - que pode, contudo, ser-lhe estranhamente semelhante e quase idêntica" (p. 23). É assim que a série das letras $\mathrm{A}, \mathrm{Z}, \mathrm{E}, \mathrm{R}, \mathrm{T}$ disposta no teclado de uma máquina de escrever não constitui um enunciado, mas seria o campo enunciativo no qual aparece como elemento singular e não é mais uma sequência de letras traçada ao acaso e de forma aleatória. $\mathrm{O}$ enunciado supõe sempre uma singularidade. 
A partir da reflexão de Deleuze, entendemos que o problema teórico de Foucault incidia em "saber em que consistem essas singularidades que o enunciado supõe" (FOUCAULT, p. 23). Para Deleuze, tal questionamento não é solucionado por Foucault e permanece sem solução até o final de "A Arqueologia do Saber", pois esta questão "ultrapassa os limites do 'saber" (p. 23; grifos do autor) e já anuncia a questão do poder a ser apresentada nas obras seguintes escritas por Foucault. Neste caminho, a exposição de Deleuze sobre o Foucault arquivista deixa evidente que o leitor precisa intuir sobre o problema do poder associado ao saber, como uma questão que corresponde ao "novo domínio" do pensamento foucaultiano, mas que a será tratado apenas nas obras posteriores.

Deleuze ressalta que o enunciado pressupõe raridade, na medida em que "não apenas poucas coisas sejam ditas", mas, "porque poucas coisas realmente possam ser ditas" (DELEUZE, 2005, p. 15; grifos do autor). A exaustiva leitura de Deleuze mostra que os enunciados existem dentro de três fatias de espaço que permitem a sua singularidade que, entretanto, promovem acúmulo ou efeito dessa raridade: $\mathrm{O}$ primeiro é o espaço colateral, associado ou adjacente, formado por outros enunciados do mesmo grupo; o segundo é espaço correlativo: que trata da relação do enunciado com os seus sujeitos, seus objetos e seus conceitos; a terceira fatia, explica Deleuze, é o espaço complementar, ou formações não-discursivas, quais sejam, "instituições, acontecimentos políticos, práticas, processos econômicos” (p. 21; grifos do autor). É dessa forma que Foucault define o discurso como sendo "um conjunto de enunciados, na medida em que se apoia na mesma formação discursiva" (2004, p. 132). Foucault ainda esclarece que o discurso "não forma uma unidade retórica ou formal, indefinidamente repetível e cujo aparecimento ou utilização poderíamos assinalar (e explicar, se for o caso) na história” (p.132). Constitui-se “de um número limitado de enunciados" (p. 132) e segundo regras de existência no campo indeterminado da história:

O discurso, assim entendido, não é uma forma ideal e atemporal que teria, além do mais, uma história; o problema não consiste em saber como e por que ele pode emergir e tomar corpo um determinado ponto do tempo; é, de parte a parte, histórico - fragmento de história, unidade e descontinuidade na própria história, que coloca o problema de seus próprios limites, de seus cortes, de suas transformações, dos modos específicos de sua temporalidade, e não de seu surgimento abrupto em meio às cumplicidades do tempo. (FOUCAULT, 2004, p. 133). 
Assim, ressaltamos com Deleuze que, na perspectiva foucaultiana, a análise enunciativa é, pois, uma análise histórica: aos enunciados pergunta-se "de que modo existem, o que significa para eles o fato de se terem manifestado, de terem deixado rastros e, talvez, de permanecerem para uma reutilização eventual"; o que é para elas o fato de terem aparecido - e nenhuma outra em seu lugar (Foucault, 2004, p. 124)

Para os estudos gramaticais uma unidade elementar pode ser isolada em uma frase ou em uma proposição, descrever essas unidades significa isolá-las e caracterizálas gramatical e estruturalmente. Entretanto, nos estudos discursivos foucaultianos, descrever um enunciado significa definir as condições pelas quais uma série de elementos sígnicos apresentou uma existência específica. A formação discursiva é, portanto, a unidade que se constata nas regularidades entre objeto, conceito, teoria e sujeito, numa série de enunciados, o que permite definir, por exemplo, o discurso sobre a educação, a leitura, a literatura.

É neste caminho que nos perguntamos quais sujeitos estão envolvidos, em quais posições e o que enunciam sobre a leitura/quais arquivos de enunciados são formados a partir dessas leituras e os que são excluídos, apagados, silenciados nessa prática?

O enunciado pressupõe uma função de existência e apresenta quatro características: a primeira delas é a de que o enunciado possui um referencial constituído de leis de possibilidade, ou regras de existência para os objetos que se encontram nomeados ou descritos e para as relações que se encontram nomeados ou descritos e para as relações que se encontram confirmadas ou negadas; a segunda característica diz respeito a existência de em um sujeito que fala, mas não um sujeito transcendental ou antropológico, mas uma posição de sujeito funcionando, que pode ser ocupada por diferentes indivíduos, sob certas condições.

Como terceira característica de existência dos enunciados, Foucault ressalta que está ligado a um domínio associado ou domínio de memória que lhe apresenta relações com o passado e lhe abre um futuro eventual e que é constituído pelo conjunto de formulações no interior das quais o enunciado se inscreve e com os quais poderá se apagar ou ser valorizado, conservado, cristalizado, repetido, modificado, atualizado e oferecido como objeto a discursos futuros. Por fim, o enunciado possui existência material repetível que lhe é constitutiva e é da ordem da Instituição, ao mesmo tempo em que entram em redes; coloca-se em campos de utilização, transformação e a modificações possíveis. 
Pensemos, hoje, nos enunciados "Quem matou Marielle Franco?”, “Quem mandou matar Marielle Franco?”, “Marielle, presente!", “Quem matou Marielle e Anderson Silva?". Como/quanto foram e são muitas vezes repetidos e retomados após o assassinato da vereadora e ativista carioca e o motorista Anderson, para dizermos que tais enunciados já fazem parte do arquivo da história recente da política no país. Estes se associam a outros ditos singulares e únicos no momento atual das lutas e resistências das sujeitas negras, tais como: "Resistimos" "Marielles", "Não vão nos calar" e a outros movimentos que se fortaleceram nas lutas contra o genocídio negro e a favor dos direitos das mulheres e homens negras e negros, estão nas histórias das mulheres e homens e atualizam os lugares materiais e simbólicos anteriores - quilombos, Zumbis e Dandaras - são atualizados, associados às suas lutas e sua inscrição nos corpos dessas sujeitas e sujeitos negras/os na história política do país hoje. Nessa direção de pensar o enunciado em sua relação com o processo de subjetivação, tomemos agora o espaço de escrita do próprio Michel Foucault, a partir da noção de eu-enunciado que estamos desenvolvendo, considerando a posição de sujeito de uma escritura, para entender o funcionamento do sujeito-autor de "A Arqueologia do Saber".

\section{O escritor e o eu-enunciado n’ A Arqueologia}

Ler Foucault é muito desafiador. Não é somente uma leitura para obter conhecimento, para fundamentar nossas questões de pesquisa, para nos enquadrar num campo teórico e ter reconhecimento acadêmico. Ler Foucault é ser desafiado a cada linha escrita. É estar em confronto com outro eu que nos instiga, nos incomoda, nos irrita, nos faz infames leitores por percebermos nossa pequenez conteudística. Ler Foucault é nos encontrar no limiar dos atravessamentos possíveis, na instabilidade dos sentidos produzidos, no lugar da tessitura filosófica, nas amarras das teias de saberes e poderes que nos constituem cotidianamente.

Ler Foucault opera deslocamentos. Isso é o que nos move para um outro lugar: o da escritura foucaultiana, como espaço de produção de uma linguagem ao infinito, natural da posição de autor que lança sua flecha, cuja discursividade implicada inicia um movimento não-linear, disperso, mas que acusa uma posição de autor em funcionamento. Começamos, então, a olhar para o movimento feito pelo Foucault escritor desde a orelha do livro, destacando a seguinte pergunta :

Com que propósito escrevi este livro? Para explicar o que quis fazer nos livros precedentes em que tantas coisas ficaram obscuras? Não só, nem exatamente, mas, indo um pouco mais longe, para retornar 
como que por uma nova volta de espiral, a um ponto anterior ao que havia empreendido; mostrar de onde eu falava; demarcar o espaço que torna possíveis essas pesquisas e outras talvez que jamais concluirei; em suma, para dar significação à palavra arqueologia que eu havia deixado vazia. (FOUCAULT, 2004).

Um esclarecimento feito por Foucault? Uma satisfação para seus leitores curiosos? Não. Um torcer-se sobre si, uma dobra que parece própria da posição foucaultiana de escritor. A "nova volta de espiral” para demarcar espaço. Foucault escritor dobra-se para falar de si, constituindo-se neste movimento em espiral. A escritura tem esta função enunciadora de nos torcer sobre nós mesmos, dizendo quem somos, ao falar de outras coisas, ao falar de arqueologia(s).

Este movimento espiralar acontece exatamente para "dar significação à palavra arqueologia", palavra que ele considera perigosa, na continuidade de seu texto-orelha do livro, pois "evoca rastros caídos fora do tempo", tratando-se de descrever discursos, não livros, não teorias, mas conjuntos familiares e enigmáticos, nas palavras do próprio Foucault, unidades que formam domínios autônomos, mas não independentes, regrados, em contínua transformação e sem sujeitos, mesmo integrando obras individuais. Retomamos aqui essa escritura para fazer aparecer um lugar de autor, não da ordem do nome próprio, que assina uma obra, mas um lugar de escritura que subjetiva, produz sujeitos e produz uma discursividade nova, sem molduras fixas, sem o estriamento próprio das normalizações escriturísticas, uma escritura arqueológica, cujos saberes produzidos se dão na dispersão dos enunciados.

Cabe insistir em perguntar qual o lugar do enunciado n' A Arqueologia? O enunciado compõe uma engrenagem juntamente com os discursos e os sujeitos produzidos. Esta engrenagem arqueológica foucaultiana acusa a natureza instável, sempre em movimento do enunciado, que não é da ordem do linguístico, como já dissemos, mas da ordem dos acontecimentos e possui certa regularidade que é responsável por sua (trans)formação. "Assim, o enunciado circula, serve, se esquiva, permite ou impede a realização de um desejo, é dócil ou rebelde a interesses, entra na ordem das contestações e das lutas, torna-se tema de apropriação ou de rivalidade (FOUCAULT, 2004, p. 119)".

O enunciado foucaultiano é da ordem do funcionamento discursivo e da subjetivação e está diretamente ligado à produção dos discursos que, por sua vez, constitui o arquivo. Este reúne as condições históricas para existência dos enunciados, sua produção, (des)aparecimento, sujeições e rupturas. $\mathrm{O}$ arquivo, claro, está sujeito às 
relações de saber/poder, podendo funcionar no interior de um dispositivo, de acordo com toda rede de elementos discursivos ou não-discursivos que buscam exercer o controle dos sujeitos.

Por esse termo tento demarcar, em primeiro lugar, um conjunto decididamente heterogêneo que engloba discursos, instituições, organizações arquitetônicas, decisões regulamentares, leis, medidas administrativas, enunciados científicos, proposições filosóficas, morais, filantrópicas. Em suma, o dito e o não dito são os elementos do dispositivo. O dispositivo é a rede que se pode estabelecer entre estes elementos (FOUCAULT, 2015, p. 364).

A língua funcionando como controle dos sentidos produzidos, das formas delineadas, dos sujeitos autores. Necessário se faz acompanhar, portanto, o movimento foucaultiano de escrituração de seus textos, na direção de resistir e reinventar-se nesta luta com o espaço sempre cheio de contornos que é a escritura, onde insurge o euenuciado foucaultiano.

$\mathrm{Na}$ introdução desta obra, Foucault continua apresentando os indícios de sua escritura em espiral. Defendendo uma perspectiva da história não-linear, Foucault anuncia sua "empresa", cujo perfil foi traçado pela "História da loucura", "Nascimento da clínica" e em "As Palavras e as coisas", que ele ressalta ter feito "muito imperfeitamente":

Trata-se de uma empresa pela qual se tenta medir as mutações que se operam, em geral, no domínio da história; empresa onde são postos em questão os métodos, os limites, os temas próprios da história das ideias; empresa pela qual se tenta desfazer as últimas sujeições antropológicas; empresa que quer, em troca, mostrar como essas sujeições puderam-se formar. Estas tarefas foram esboçadas em uma certa desordem, e sem que sua articulação geral fosse claramente definida. Era tempo de lhes dar coerência - ou, pelo menos, de coloca-las em prática. O resultado desse exercício é este livro. (FOUCAULT, 2004, p. 17).

Foucault escritor fala de seu projeto de escritura, que resulta na produção de "A Arqueologia do Saber”. De uma escrita que não cristaliza, não imobiliza, mas dá conta de movimentações, desconstruções e (des)subjetivações, que dá conta de estabelecer a coerência de tarefas "esboçadas numa desordem", na dispersão de suas obras, como exercício que resulta no livro d'A arqueologia. Na linha deste desafiar-se na escritura, Foucault, ainda na introdução do livro, insurge com um diálogo, ou melhor, talvez um duelo:

- Você não está seguro do que diz? Vai novamente mudar, deslocarse em relação às questões que lhe são colocadas, dizer que as objeções não apontam realmente para o lugar que você se pronuncia? 
Você se prepara para dizer, ainda uma vez, que você nunca foi aquilo que em você se critica? Você já arranja a saída que lhe permitirá, em seu próximo livro, ressurgir em outro lugar e zombar como o faz agora: não, não, eu não estou onde você me espreita, mas aqui de onde o observo rindo. (FOUCAULT, 2004, pag. 19).

- Como?! Você pensa que eu teria tanta dificuldade e tanto prazer em escrever, que eu teria me obstinado nisso, cabeça baixa, se não preparasse - com as mãos um pouco febris - o labirinto onde me aventurar, deslocar meu propósito, abrir-lhe subterrâneos, enterrá-lo longe dele mesmo, encontrar-lhe desvios que resumem e deformam seu percurso, onde me perder e aparecer, finalmente, diante de olhos que eu não terei mais que encontrar? Vários, como eu sem dúvida, escrevem para não ter mais rosto. Não me pergunte quem sou e não me diga para permanecer o mesmo: é uma moral de estado civil; ela rege nossos papéis. Que ela nos deixe livres quando se trata de escrever. (FOUCAULT, 2004, p. 20)

Este diálogo-duelo é esplêndido para pensar no Foucault escritor e seu processo de subjetivação pela escritura. Marca-se o lugar do sujeito que escreve, afastando-se de si ao enunciar-se, ao se encontrar na posição de autor. Movimento semelhante ao do pintor no quadro de Velazquez, Las meninas, o qual se afasta para olhar para fora de sua obra, coincidindo seu olhar com o de quem o vê pintar uma cena. Quanto mais distante de si, mais insurge seu eu-enunciado, eu-autor. O embate também é institucional, rejeitando e resistindo a esta posição de escritor como algo fixo, louvável, da ordem moral de um estado civil: "Que ela nos deixe livres quando se trata de escrever" (FOUCAULT, 2004, p. 20). Uma verdadeira insurreição escriturística. Engana-se quem acha que está preso ao sistema de escrita, ao sistema gramatical, linguístico, ao sistema de autoria. $\mathrm{O}$ eu-enunciado encontra suas brechas e resiste.

Faremos, como Foucault, um retorno, um movimento sobre o si da escritura de “A Arqueologia do Saber" para acompanhar este movimento do autor. Vamos à versão inédita, não publicada, da introdução da obra, disponibilizada no "Cahier de l'Harne", por Artières, Bert, Gros e Revel (2004). A consideração desta versão é de extrema importância, por ter sido base para a perspectiva do eu-enunciado que, neste artigo, se faz emergente para pensar na subjetivação de Foucault como autor. Serão apresentadas, a seguir, algumas imagens feitas de quatro páginas da referida obra, nas quais é possível acompanhar este movimento do Foucault escritor.

Trata-se da primeira versão manuscrita do capítulo de abertura do que se tornaria “A Arqueologia do Saber". Os autores destacam que só foram retranscritas as passagens não riscadas por Foucault e que a transcrição foi realizada por Frédéric Gros. Intitulado 
"O livro e o sujeito", o texto inicia remetendo à ideia de empresa que destacamos alhures.

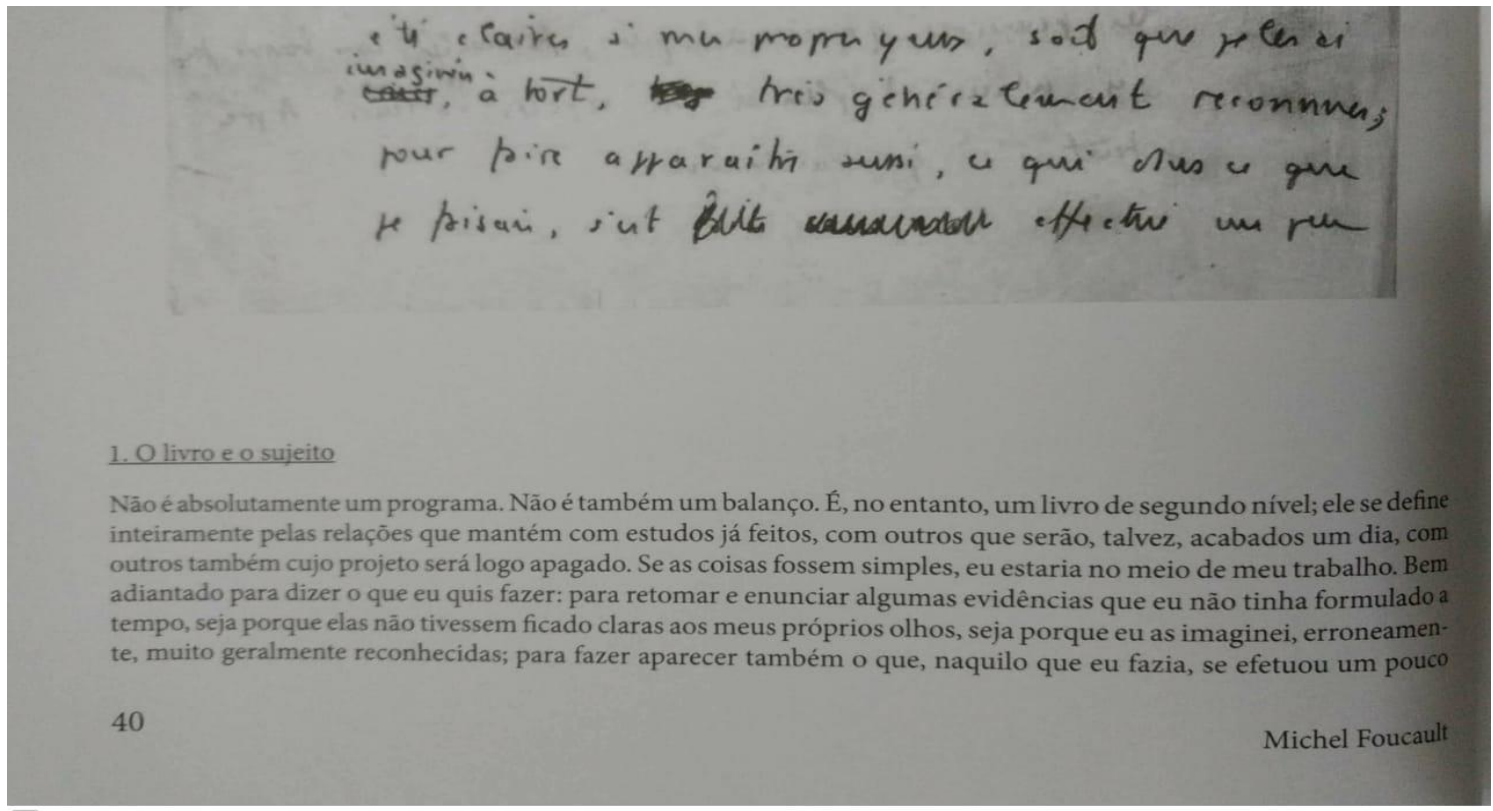

(ARTIÈRES, BERT, GROS, REVEL, 2014, p. 40)

Nesta primeira versão não publicada, Foucault inicia alertando: "Não é absolutamente um programa" (ARTIÈRES et al, 2014, p. 40), como também diz não ser um balanço. O livro “A Arqueologia do Saber" define-se, nas palavras do autor, “inteiramente pelas relações que mantém com estudos já feitos, com outros que serão, talvez, acabados um dia, com outros também cujo projeto será logo apagado”. Este alerta anunciado já funciona marcando o lugar insurgente do sujeito escritor e de sua relação com o livro, em seu movimento de aproximação e distanciamento da escrita produzida. O sujeito da escritura é, portanto, um sujeito insurgente, dado a resistir, infiltrar-se nas ordens escriturísticas para propor novas direções, meadas inusitadas que possibilitam dar visibilidade aos pontos que não estavam evidentes.

Continuamos seguindo as pistas destes movimentos de Foucault, na direção do que o constitui sujeito-enunciado, sujeito que a cada produção escriturística, ao invés de sujeitar-se a uma ordem que o nomeia como autor de uma obra, distancia-se desta linguagem que o identifica, sendo subjetivado por ela, pois, na posição de autor apenas lançará a flecha, possibilitando a produção de uma discursividade ao infinito:

(...) $\mathrm{O}$ espelho ao infinito que toda linguagem faz nascer assim que ela se insurge verticalmente contra a morte, a obra não o tornava visível sem rechaçá-lo: ela colocava o infinito fora dela mesma infinito majestoso e real do qual ela se fazia o espelho virtual, circular, rematado em uma bela forma fechada. (...) Escrever, hoje, está infinitamente próximo de sua origem. Isto é, desse ruído 
inquietante que no fundo da linguagem anuncia, logo que se abre um pouco ao ouvido, aquilo contra o que se resguarda e ao mesmo tempo a quem nos endereçamos. (FOUCAULT, 2015, p. 53).

Foucault, sempre se colocando neste lugar de pensar a relação sujeito/linguagem, numa luta nada vã com as palavras, mas numa luta que desestrutura, incomoda, desafia, inquieta e faz insurgirem novos elementos. $\mathrm{Na}$ introdução não publicada de "A Arqueologia do Saber", fica bem visibilizada esta forma de Foucault se posicionar diante do que escreve, ou melhor, de se dar conta de que não está numa posição privilegiada:

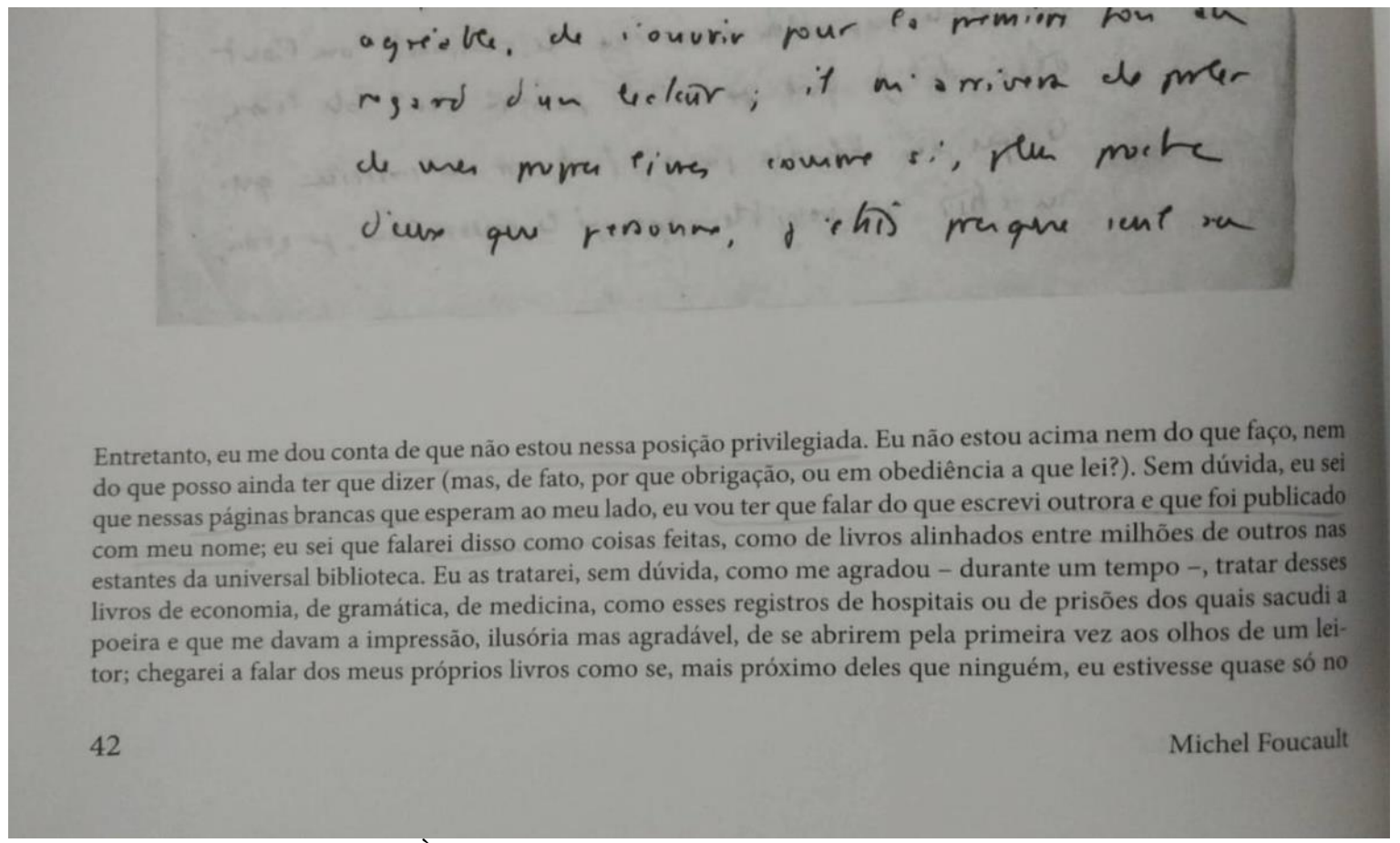

(ARTIÈRES, BERT, GROS, REVEL, 2014, p. 42)

Ao mesmo tempo em que reconhece certo sujeitamento à publicação "em seu nome", a uma ordem do sistema de publicação, coloca-se no lugar de quem "sabe" que tudo isso foi por escolher tratar do que o agradou e o possibilitou "sacudir a poeira", dando-lhe a impressão de dar a ver ao leitor muitas coisas, pela primeira vez. No fundo, esta é a posição que Foucault ocupa: de falar das brechas, das inquietações, das margens. E é desse lugar "não privilegiado" que Foucault se confronta, começando a fazer aparecer este eu-enunciado, que vai se (des)subjetivando ao longo de sua escritura, serpenteando em meio ao autor que precisa nomear a si, mas reconhece este $e u$ que o persegue: 


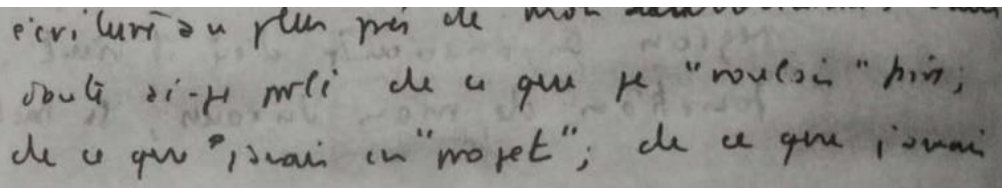

sujeito, eu desejaria ter-me sentido atravessado por uma linguagem assim; eu desejaria ter sido o invisivel stporte de um texto que não tivesse nome. E essa linguagem, no dia, enfim, em que eu tivesse ajeitado bastante vazio em torno de mim e em mim, para lhe dar acesso, eis que ela me chega (para minha surpresa, devo di zer, mais que para meu despeito) conjugada do começo ao fim na primeira pessoa. Há já 10 páginas e mait de um dia que eu digo "Eu", obstinadamente, sem ser capaz, parece-me, de pronunciar uma só frase impesso al. Devo reconhecer, no entanto, que é um "eu" bem abstrato. Não é minha biografia intelectual que empre endo, à maneira desse exercício que os universitários alemães praticavam outrora com tanta complacṫ cia. Não tento também dar uma linguagem ao que sinto atualmente, nem juntar minha escrita o mais perto de meu presente. Sem dúvida falei do que eu "queria" fazer; do que eu tinha como "projeto"; do que eu

(ARTIÈRES, BERT, GROS, REVEL, 2014, p. 48)

"Há já 10 páginas e mais de um dia que eu digo "Eu”, obstinadamente, sem ser capaz, parece-me, de pronunciar uma só frase impessoal. Devo reconhecer, no entanto, que é um "eu" bem abstrato" (ARTIÈRES, BERT, GROS, REVEL, 2014, p. 48). Fiquemos atentos a esta distinção: o Eu com maiúscula, da escrita, que enuncia a si num tempo/espaço da escritura em seu fazer-se, e o "eu”, abstrato que, como Foucault ressalta, não é sua biografia intelectual que empreende, à moda de como universitários alemães o praticavam, nem juntar à escrita o que tem de mais perto dele como seu presente, ainda que falasse do que desejava, do que tinha esperado ou ignorado. E se fosse isso o que desejasse fazer, não seria desta maneira. Enfim, nesta introdução não publicada, não enunciada, invisibilizada, mas rascunhada, estava aquilo que hoje estamos chamando de eu-enunciado.

Como avaliar este lugar de fala? Seria um "eu" abstrato, que também não intenciona uma biografia? Há um eu, que é enunciado e que, provavelmente, se distingue pelo exercício de saber/poder, a partir do qual a linguagem é uma força que incide sobre outros sujeitos, pela distinção estabelecida. E retomando e parafraseando a epígrafe deste artigo, neste gesto de escrita, ao contrário, o sujeito que escreve não pára de desaparecer. Quanto mais enuncia a si, mais desaparece o "eu sou" da escrita. Este 'eu' seria, então, não um eu-institucional, um eu que se institui a si, mas um eu diferente, que se constitui como eu-enunciado foucaultiano. Vejamos: 


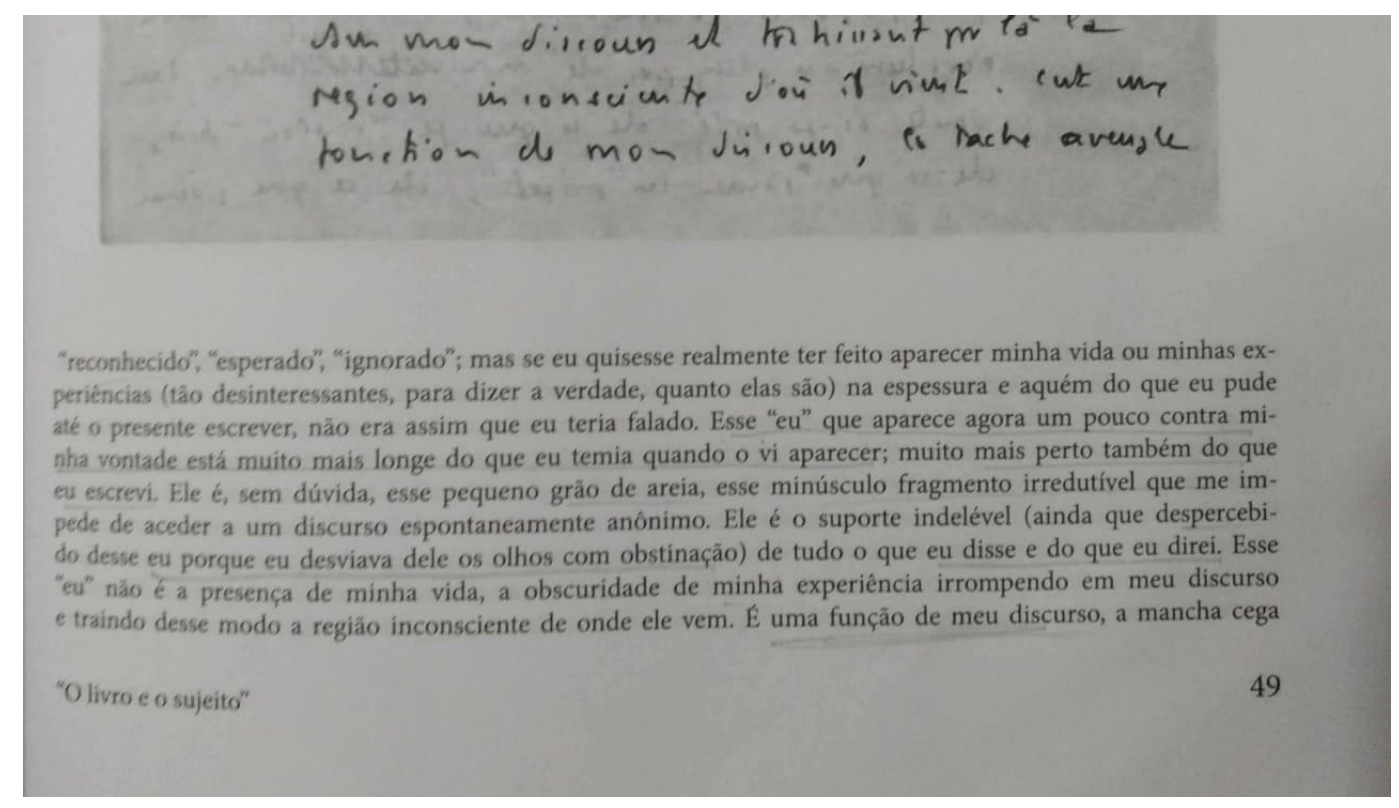

(ARTIÈRES, BERT, GROS, REVEL, 2014, p. 49)

"Esse "eu" que aparece agora um pouco contra minha vontade está muito mais longe do que eu temia quando o vi aparecer; muito mais perto do que eu escrevi" (ARTIÈRES, BERT, GROS, REVEL, 2014, p. 49). Este "eu-enunciado" é da contraordem do desejo, é da ordem do seu desaparecimento. Longe da vontade de ser enunciado e perto do ser escriturado. Este eu que não resulta na ascese de um ser do discurso "espontaneamente anônimo", como destaca Foucault, mas se configura como este "suporte indelével” de tudo que disse e dirá, que não é presença em sua vida, mas a obscuridade de sua própria experiência que irrompe, traindo seu lugar inconsciente de partida, sendo uma função de seu discurso. Retomando, mais uma vez, a epígrafe deste artigo, "o sujeito que escreve não para de desaparecer".

\section{Considerações finais}

Relembramos nosso objetivo inicial de dar visibilidade ao Foucault escritor e arquivista, como sujeito que enuncia a si, ao desenvolver seu método arqueológico em "A Arqueologia do Saber". Para tanto, tomamos a orelha e introdução da obra, da edição de 2004, para destacarmos o processo de subjetivação do Foucault escritor, confrontando-se com elementos de um dispositivo que produz linhas de força sobre seu projeto de empreender o quadro teórico-metodológico da produção do saber.

Olhamos para onde Foucault olhou ao propor enunciar a si enquanto autor, neste movimento sinuoso, não-linear, sempre atento, desconfiado, propondo novos percursos de escritura quando se dá conta dos atravessamentos que se impõem como força controladora de sua escritura. Neste momento, seu projeto de escritura rompe com as 
amarras institucionalizadoras dos sistemas de escrita. A escrita de "A Arqueologia do Saber", ao mesmo tempo em que deu conta de preencher determinados espaços que Foucault julgara ainda vazios, na rede de seus "projetos" de escritura, também insurgiu como espaço para pensar e propor um novo modo de ler a história e a constituição dos saberes, inclusive sobre o ser da linguagem, sobre a produção de enunciados e a constituição de arquivos.

Por fim, ao tomar como leitura a versão da introdução que não foi publicada, mas tornada pública em 2014, numa publicação organizada conjuntamente por Artières, Bert, Gros e Revel, na qual é disponibilizada a versão manuscrita e a sua transcrição, pudemos conhecer um Foucault que, entre outros pontos de sua escritura, tematizou e fez aparecer o eu-enunciado, num gesto de quem quanto mais escreve, mais desaparece. Consideramos este olhar para o Foucault escritor e arquivista, portanto, como uma abordagem relevante para se pensar nas práticas discursivas com leitura e escritura, bem como para análise da produção foucaultiana em si, pelos seguintes pontos: i) por apontar para uma estética autora, que se subjetiva ao olhar para si, na insurgência de um duplo da/na linguagem ii) por reunir elementos para uma prática escriturística arqueológica, que explica o modo como Foucault escreve; iii) por marcar a posição de autor como não subordinada a uma ordem institucional da escritura, mas como insurgente.

\section{Referências}

ARTIÈRES, Philippe, BERT, Jean-François, GROS, Frédéric, REVEL, Judith (orgs.). Michel Foucault. Revisão técnica de Manoel Barros da Motta. Tradução de Abner Chiquieri. $1^{\text {a }}$ edição. Rio de Janeiro: Forense, 2014.

DELEUZE, Gilles. Foucault. Tradução Claudia Sant'Anna Martins; revisão da tradução Renato Ribeiro. São Paulo: Brasiliense, 2005.

FOUCAULT. Michel. Ditos e Escritos II - Arqueologia Das Ciências e História Dos Sistemas de Pensamento. Organização e seleção de textos Manoel Barros da Motta; tradução Elisa Monteiro. - 3. ed. - Rio de janeiro: Forense Universitária, 2013.

FOUCAULT, Michel. A arqueologia do saber. Tradução de Luiz Felipe Baeta Neves. $7^{\text {a }}$ edição. Rio de Janeiro: Forense, 2004.

FOUCAULT, Michel. Estética: literatura, pintura, música e cinema. Organização e seleção de textos Manoel Barros da Motta; Tradução Inês Autran Dourado Barbosa. $4^{a}$ edição. Rio de Janeiro: Forense Universitária, 2015. (Ditos e escritos III)

FOUCAULT, Michel. Microfísica do poder. Organização, introdução e revisão técnica de Roberto Machado. 2a edição. Rio de Janeiro: Paz e Terra, 2015.

GREGOLIN, Maria do Rosário. O dispositivo escolar republicano na paisagem das cidades brasileiras: enunciados, visibilidades, subjetividades. Revista Moara - Edição 43 - jan - jun 2015, Estudos Linguísticos. 